\title{
Depressions caused by localized subsidence in the Netherlands, Belgium and Germany: a link with coal mining?
}

\author{
Geert-Jan Vis ${ }^{1}$, Erik van Linden ${ }^{2,1}$, Ronald van Balen ${ }^{3,1}$, and Kim Cohen ${ }^{2}$ \\ ${ }^{1}$ TNO - Geological Survey of the Netherlands, Utrecht, 3584 CB, the Netherlands \\ ${ }^{2}$ Faculty of Geosciences, Utrecht University, Utrecht, $3584 \mathrm{CB}$, the Netherlands \\ ${ }^{3}$ Faculty of Earth and Life Siences, VU University Amsterdam, Amsterdam, $1081 \mathrm{HV}$, the Netherlands \\ Correspondence: Geert-Jan Vis (geert-jan.vis@tno.nl)
}

Published: 22 April 2020

\begin{abstract}
In the coal mining districts of the Netherlands, Belgium and Germany, we identified 662 previously unidentified depressions at the land surface using LIDAR data. Their density decreases westwards along with deepening of the Carboniferous coal layers, while not changing in dimensions. The timing of their formation based on historical maps and landowner reports, suggests that they mostly formed during the period 1920-1970, the peak of mining activity. Based on their position, density and age, we link the formation of depressions to the coal-mining activities in South Limburg, Germany and Belgium. Our working hypothesis tentatively explains the origin, mechanism of formation and timing of these local subsidence features.
\end{abstract}

\section{Introduction}

Coal mining in the Netherlands started in the 11th century around the monastery of Rolduc in the east of South Limburg (Fig. 1). The coals were extracted using horizontal tunnels entering the Carboniferous coal-bearing formations from river valleys (adits). Around the end of the 19th century technological advances such as groundwater extraction made it possible to scale-up coal extraction using deep subsurface mines. Since then, both private and state mines extracted coal from ever greater depths of up to around $1100 \mathrm{~m}$ in State Mine Hendrik (Fig. 1).

The last coal mines in South Limburg closed in the late 1960s and the last groundwater pump was shut down in 1994. The extraction of multiple coal seams affected the land surface in several ways. The cumulative land-subsidence reached up to $10 \mathrm{~m}$ locally, after half a century of coal mining. Accommodation of the overburden to the cavities resulted in thresholds or steps (drempels in Dutch) at the surface, which damaged numerous houses and infrastructure. The coal extraction also resulted in localized sinkholes. It was initially assumed that land-surface deformation would cease after the closure of the mines. However, in 2011 a shopping mall in Heerlen (Fig. 1) was partly evacuated after cracks in the construction had been observed. A sinkhole was discovered below one of the columns of the structure, which was the result of shallow extraction of a coal seam (Chang and Hanssen, 2014). The goaf (i.e. the part of a mine where the coal has been removed) became hydrologically connected to the overburden and sediments flowed into the cavity. In 1956, thresholds had been observed at this location (De Vent, 2016), but this information was not used until recently. The sinkhole triggered large-scale investigations issued by the Dutch state, which demonstrated that effects of coal mining can still be detected today.

One such effect is regional uplift of the land surface related to flooding of the mines following the end of groundwater extraction in 1994. This uplift can be imaged using InSAR data and reaches up to several decimetres (Pöttgens, 1985; Wings et al., 2004; Caro Cuenca et al., 2013). While space-born InSAR registers land-surface movement through time, air-born LIDAR elevation data can be used to observe present-day land-surface morphology in unprecedented detail. This study presents surface observations in the mining concessions using LIDAR data and provides a first-order interpretation. 


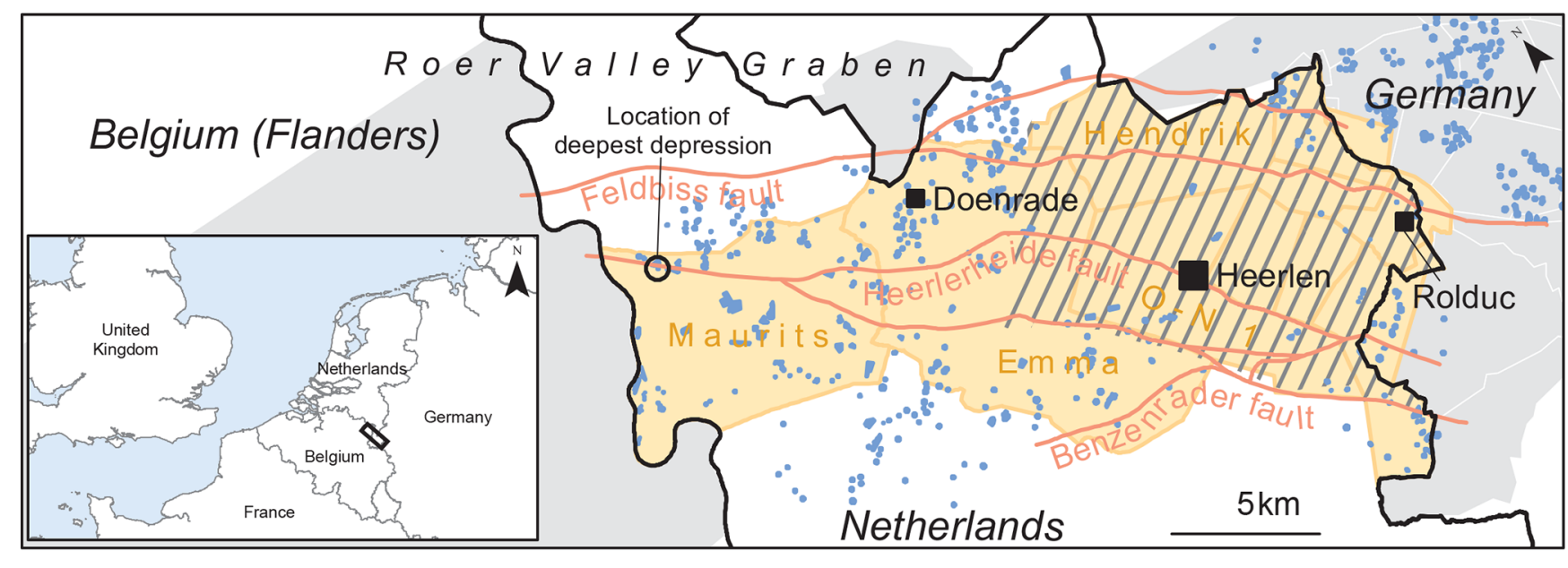

Mapped depressions (LIDAR)

Coal concessions Netherlands

Major faults at surface

Heavily built-up municipality

Coal concessions Belgium and Germany

Figure 1. Study area in South Limburg, the Netherlands, including depressions in the coal mining area. Main map is rotated. The shown fault lines represent their expression at surface. Where the faults cut the Carboniferous at depth, they are located further towards the Roer Valley Graben (northwest ward). Few depressions were observed in heavily built-up areas.

\section{Data and methods}

Laser Imaging Detection And Ranging (LIDAR) is a technique which measures the distance to the land surface from an airplane using laser pulses. We used publicly available LIDAR data from Belgium (DHMV II, 2019, $1 \times 1 \mathrm{~m}$ resolution), the Netherlands (AHN v2, 2019, $0.5 \times 0.5 \mathrm{~m}$ resolution) and Germany (OpenNRW, 2019, $1 \times 1 \mathrm{~m}$ resolution) to image surface morphology. The data we used, had non-natural surface features removed and a hillshade effect had been applied to better visualize thresholds and depressions. Interferometric Synthetic Aperture Radar (InSAR) is a remote sensing technique which utilizes radar measurements by satellites. The accuracy of InSAR is in the order of $1 \mathrm{~mm} \mathrm{yr}^{-1}$ (Vervoort and Declercq, 2018). The strength of this type of measurement comes from Persistent Scatters (PS). These are points that are stable reflector points and do not change location and dimensions over time, such as buildings or roads. Every consecutive satellite pass results in a new height measurement. When combining successive images of these PS, a very precise and accurate surface deformation time-series is generated.

Scanned and geo-referenced historical mine charts (Anonymous, 2016), provided insight into timing and origin of surface deformations related to mining activities. Historic topographic maps available from The Netherlands' Cadastre, Land Registry and Mapping Agency (Kadaster) were used to identify and date depressions that grew during historic times. The maps were made systematically since the middle of the 19th century (every 5-10 years). Fieldwork was used to drill boreholes of up to two metres depth in prominent depressions. Statements from land owners and farmers were taken to increase the understanding of depressions formation timing.

\section{Results}

\subsection{Depressions in rural areas}

In rural areas in the Dutch coal mining district and up to $7.5 \mathrm{~km}$ into neighbouring Germany, we identified and mapped 662 depressions using LIDAR data (Fig. 1). The depressions show a high density in the German coal-mining districts. In a westward direction, their density decreases via the Netherlands (South Limburg) into Flanders. This trend correlates with a westward increasing depth of the Carboniferous coal seams, from tens of meters to more than $1000 \mathrm{~m}$. The depressions are circular to ellipsoid in shape, 50-200 m wide and $0.5-2 \mathrm{~m}$ deep at their centre (Fig. 2). They were encountered several kilometres outside of the mining concessions. Field visits confirmed their visibility in the landscape. Their size, shape, number and aerial distribution rejects an origin by digging or other similar human activity.

The outlines of depressions as observed using LIDAR data, were overlain on historical topographic maps to estimate their time of formation. Many depressions show overlap with depressions indicated on the maps; contour lines can be seen to delineate circular features (Fig. 3). During the peak of coal mining (1920-1970) most depressions appeared on historical maps. A landowner reported that one of the depressions south of the village of Doenrade, northwest of Heerlen (Fig. 1), was deepening during several years more than ten years ago and has since stabilized. At another nearby location, two depressions occur on either side of the Maas- 

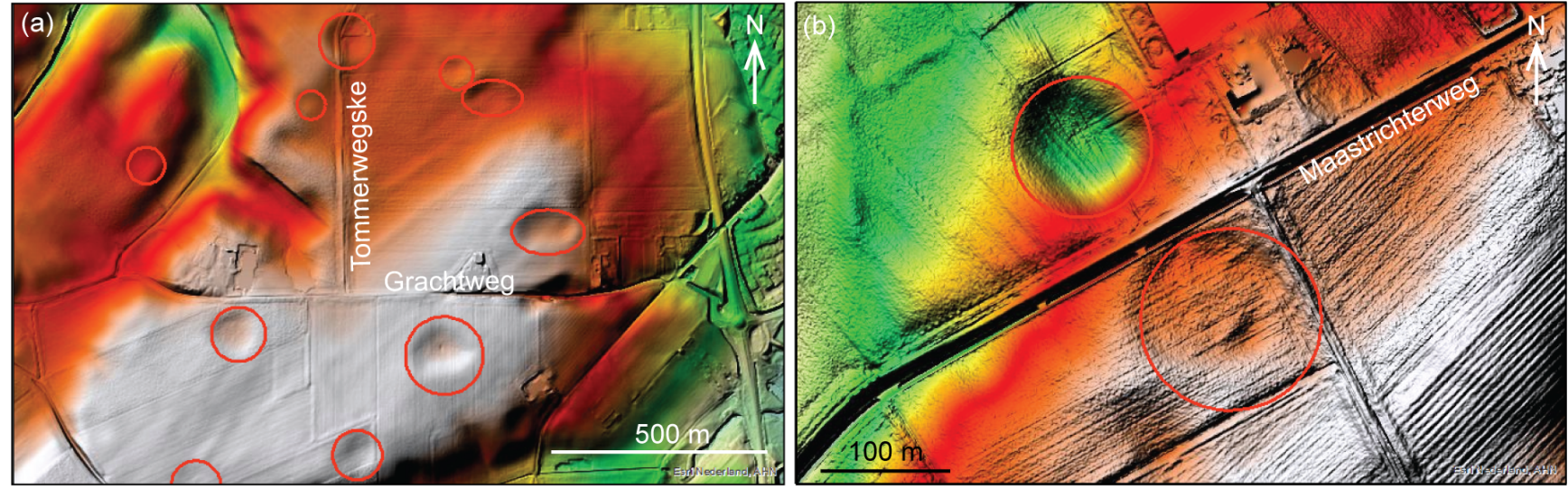

Figure 2. Observations using LIDAR data in South Limburg; (a) depressions in an agricultural area west of Schinveld, (b) one filled depression south of the road and one unchanged depression north of the road southwest of Doenrade. LIDAR AHN v2 (2019) data visualized by ESRI Netherlands.

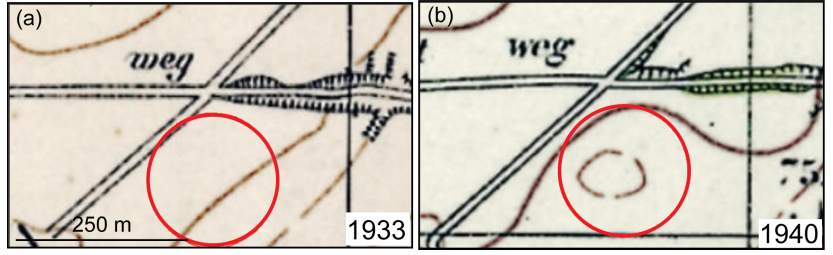

Figure 3. The location of a present-day depression on historical maps in the Emma concession (see Fig. 1), (a) in 1933 the elevation contour lines did not show the depression, (b) seven years later the depression has appeared in the contour lines, suggesting that it formed between 1933 and 1940. Historical map (C) Kadaster, provided by ESRI Netherlands.

trichterweg (Fig. 2b). The one to the south has been filled by the landowner to make land use easier. These observations suggest that the depressions have formed during and several decades after the period of active coal mining.

One depression in the west of the coal mining area is the deepest depression we found. It reaches a depth of four metres and has a diameter of $\sim 60 \mathrm{~m}$. It lies close to the northern edge of the Maurits concession which coincides with the Heerlerheide fault (Fig. 1). Four coal seams were extracted here between 480 and $740 \mathrm{~m}$ below the surface. A manual borehole in the centre of the depression encountered about $0.8 \mathrm{~m}$ of sedimentary infill consisting of redeposited loess (silt fraction), containing pieces of cokes (product of heated coal), a flint pebble and a quartzite pebble. The sediment underneath also consisted of silt, but without any other large constituents and was similar to that on the depression shoulder. This indicates that the depression formed relatively recently and was filled by erosion from the sides, as supported by the presence of rills in the depression floor, running to the lowest point.

\subsection{Depressions in urban areas}

The presence of buildings and infrastructure limits the usability of LIDAR data for the detection of surface morphology in urban areas. The former mining district is now densely populated and many residential areas overly mining concessions (Fig. 1). Nonetheless at least one possible depression could be discerned in an urban area of the city of Heerlen, above the Oranje-Nassau I concession and within several tens of metres of the Heerlerheide fault. Houses in the depression showed signs of damage (fractures, inclined walls) and multiple stages of repair. We could not establish when damage had occurred. A quick analysis using persistant scatters (PS) from InSAR data does not indicate recent vertical differential movement in the area between 1992 and 2010.

\section{Discussion}

The most striking geomorphological observation in the coal mining districts of Germany, the Netherlands and Belgium is the presence of circular depressions at the surface. The depressions decrease in spatial density from east to west, while not changing in size. This decrease in density coincides with an increasing depth of the Carboniferous coal seams and the overlying Late Cretaceous chalk. They are similar in shape to dolines in karstic landscapes. However, the geology of the coal mining region excludes the option of karstic dolines, because the top of the Late Cretaceous chalk in the region is located at depths of $40 \mathrm{~m}$ to more than $150 \mathrm{~m}$, and it is overlain by clastic Cenozoic deposits. We consider this too deep for karstic processes to show up at the land surface. Karstic depressions further south in South Limburg, where the chalk is located at depths of less than $10 \mathrm{~m}$ have diameters of 10 $30 \mathrm{~m}$, while the depressions in the coal mining area are larger (50-200 m). 
The spatial distribution of the depressions is closely linked to the presence of coal mining concessions, although depressions have also been found several kilometres outside of concession boundaries. To explain the occurrence of depressions outside of the concession boundaries we looked at the effect of groundwater extraction. The groundwater is present in subsurface basins which do not line up with concession borders but extend further away (Caro Cuenca et al., 2013). The technique of longwall coal mining caused collapse of large underground areas and at multiple stacked levels. The subsidence caused by the collapsing mines translated to the land surface with an angle of $\sim 45^{\circ}$ relative to horizontal. Depending on the depth of the mined coal layer within the concession boundaries, the geomechanical effect of subsidence generates an area of influence at the surface which is larger than the concession itself (Booth, 2006; Yavuz, 2004). The effect of groundwater extraction likely also had an area of influence which is larger than the concessions.

Most of the depressions seem to have formed roughly between 1920 and 1970, based on historical topographic maps. Witness statements from the area suggest that further deepening did not occur during at least the last ten years, although one four-metre-deep depression seems to have been active more recently. The observations in a depression in a residential area seem to suggest recent movement, judging by the damage to houses, but InSAR data could not confirm this for the period 1992-2010.

Circular depressions as observed here have not been reported previously from a coal mining district. Bell et al. (2000) discuss the mechanism of "void migration" from collapsed goafs. Voids migrate upward when the rock roof of a mine collapses. The process is governed by the width of the unsupported span, the height of the mined layer, the shear strength of and discontinuities in the covering rocks, the thickness of the overburden and the groundwater regime. Bell et al. (2000) state that in exceptional cases void migration in excess of 20 times the height of the coal seam has been recorded. In our case where coal seams were about one metre thick, that would mean $20 \mathrm{~m}$ of vertical void migration. Possibly a combination of multiple stacked coal seams leads to even more void migration and connection to the unconsolidated Cenozoic overburden. Migration of waters from the overburden into the Carboniferous has been previously discussed by De Man (1988). He suggests that cracks and fissures in the Cenozoic overburden reach into the underlying Carboniferous, allowing for water and sediment to be transported downwards.

Our working hypothesis is that due to the extraction of complete coal seams by longwall mining, large-scale deformation took place in the subsurface, in the form of cracks, fractures and continuous deformation. This deformation was amplified by the stacking of multiple mine galleries and large-scale groundwater extraction, resulting in an increased radial-outward effect on the surface with increasing depth of coal exploitation. The thresholds which were historically mapped throughout the area may play an important role in generating preferential pathways for water and sediment transport from the land surface into the Carboniferous strata. Fine-grained particles may thus be transported downwards with the groundwater, slowly generating so-called pseudo dolines at the land surface. A similar mechanism has been proposed by Bell et al. (2000), albeit for coal seams at shallower depths. This hypothesis implies that this mechanism started to diminish as soon as groundwater extraction from the mines had ended.

\section{Conclusions}

In the coal mining district of the Netherlands, Belgium and Germany, we identified 662 previously not identified depressions at the land surface using LIDAR data. The depressions are likely linked to the mining activities. Our working hypothesis is that both geomechanical effects such as fractures leading to thresholds or steps at the surface, and hydrological processes due to groundwater extraction are the main drivers for depression formation. Future work is needed to explain the mechanism and timing in more detail.

Data availability. The datasets generated and analysed for this study are available from the corresponding author on reasonable request.

Author contributions. GJV supervised, provided resources and wrote the draft of this manuscript. EvL performed the investigation and visualized the data. RvB and $\mathrm{KC}$ conceptualized, supervised and reviewed the text.

Competing interests. The authors declare that they have no conflict of interest.

Special issue statement. This article is part of the special issue "TISOLS: the Tenth International Symposium On Land Subsidence - living with subsidence". It is a result of the Tenth International Symposium on Land Subsidence, Delft, the Netherlands, 17-21 May 2021.

Acknowledgements. We thank our colleagues at TNO - Geological Survey of the Netherlands for assistance during this project and specifically Jenny Hettelaar, Armin Menkovic and Ronald Harting.

\section{References}

AHN: Actueel Hoogtebestand Nederland, available at: https://www. ahn.nl, last access: 5 September 2019.

Anonymous: Na-ijlende gevolgen steenkolenwinning Zuid_limburg, Final report on the results of the working 
group 5.2.1 - ground movements, Ministry of Economic Affairs, the Netherlands, 222 p., available at: https://www.rijksoverheid. nl/binaries/rijksoverheid/documenten/rapporten/2016/12/ 27/na-ijlende-gevolgen-steenkolenwinning-zuid-limburg-1/ GSZL_Final_Report_WG521_groundmovements.pdf (last access: 28 February 2020), 2016.

Bell, F. G., Stacey, T. R., and Genske, D. D.: Mining subsidence and its effect on the environment: some differing examples, Environ. Geol., 40, 135-152, 2000.

Booth, C. J.: Groundwater as an environmental constraint of longwall coal mining, Environ. Geol., 49, 796-803, 2006.

Caro Cuenca, M., Hooper, A. J., and Hanssen, R. F.: Surface deformation induced by water influx in the abandoned coal mines in Limburg, The Netherlands observed by satellite radar interferometry, J. Appl. Geophys., 88, 1-11, 2013.

Chang, L. and Hanssen, R. F.: Detection of cavity migration and sinkhole risk using radar interferometric time series, Remote Sens. Environ., 147, 56-64, 2014.

De Man, Y. H. H.: Surface subsidence near Douvergenhout and in the eastern mining district South Limburg, the Netherlands, Memoirs of the Centre for Engineering Geology in the Netherlands, 88, 1988.

De Vent, I. A. E.: Tremores \& sinkholes: Unforeseen effects of mining in the Netherlands, in: Structural Analysis of Historical Constructions - Anamnesis, diagnosis, therapy, controls, edited by: Van Balen, K. and Verstynge, E., Taylor \& Francis Group, London, 338 p., 2016.
DHMV: Digitaal Hoogtemodel, available at: https://overheid. vlaanderen.be/informatie-vlaanderen/producten-diensten/ digitaal-hoogtemodel-dhmv, last acces: 5 September 2019.

OpenNRW: available at: https://open.nrw/startseite, last access: 5 September 2019.

Pöttgens, J. J. E.: Bodenhebung durch ansteigendes Grubenwasser. The developing science and art of minerals surveying, proceedings of the 6th International Congress for Mine Surveying, Harrogate, 928-938, 1985.

Vervoort, A. and Declercq, P. Y.: Upward surface movement above deep coal mines after closure and flooding of underground workings, Int. J. Min. Sci. Technol., 28, 53-59, 2018.

Wings, R. W. M. G., Miseré, W. M. H., and Pöttgens, J. J. E.: Bodensenkung - Bodenhebung - Bergschäden?, 44e Wissenschaftliche Fachtagung des Deutschen Markschneider-Verein e.V., 15-18 September 2004, Bochum, 2004.

Yavuz, H.: An estimation method for cover pressure reestablishment distance and pressure distribution in the goaf of longwall coal mines, Int. J. Rock Mechan. Min. Sci., 41, 193$205,2004$. 